\title{
ANÁLISE PRAXEOLÓGICA DO MÉTODO PEER INSTRUCTION: CONSTRUÇÃO DE UM PONTO DE REFERÊNCIA PARA O ESTUDO DE SUAS MODIFICAÇÕES E ADAPTAÇÕES PARA DIFERENTES CONTEXTOS DE ENSINO
}

\author{
PRAXEOLOGICAL ANALYSIS OF THE PEER INSTRUCTION METHOD: \\ CONSTRUCTION OF A REFERENCE POINT FOR THE STUDY OF ITS \\ MODIFICATIONS AND ADAPTATIONS FOR DIFFERENT TEACHING CONTEXTS
}

\author{
Felippe Percheron ${ }^{1}$, Ana Amélia Petter ${ }^{2}$, Tobias Espinosa ${ }^{3}$, Ives Solano Araujo ${ }^{4}$ \\ Recebido: Fevereiro/2021 Aprovado: Abril/2021
}

\begin{abstract}
Resumo: Pesquisas na área de ensino têm apontando o Peer Instruction (PI) como o método ativo de ensino mais utilizado, aplicado em diferentes contextos educacionais e, consequentemente, sujeito a diversas modificações no seu processo de implementação. Tais modificações podem se fazer necessárias para viabilizar sua aplicação em contextos diferentes para os quais foi pensado, assim como podem descaracterizá-lo, impossibilitando que sejam alcançados os resultados de aprendizagem pretendidos. No presente artigo nos propomos a realizar um mapeamento das características práticas e teóricas do $\mathrm{PI}$, buscando apresentar suas atividades e princípios de forma organizada e logicamente estruturada. Para tanto, partimos da perspectiva das Organizações Praxeológicas da Teoria Antropológica do Didático, utilizando a ferramenta analítica Organização do Método de Ensino, subdividindo a estrutura do PI em tipos de tarefa, técnicas e discursos tecnológicos. Tal análise pode contribuir com trabalhos de pesquisa e atividades de ensino que abordem o método, pois torna explícito seus componentes e aquilo que os sustenta, permitindo o estabelecimento de uma referência para avaliar modificações e adaptações no PI.

Palavras-chave: Peer Instruction; Organização Praxeológica; Organização do Método de Ensino; Teoria Antropológica do Didático.
\end{abstract}

\begin{abstract}
Research has shown the Peer Instruction (PI) method as the most used active teaching method, applied in different educational contexts and, consequently, subject to several changes in its implementation process. Such modifications may be necessary to make its application viable in different contexts, but also de-characterize it, making it impossible to achieve the intended learning results. In this article we propose to map the practical and theoretical characteristics of the PI to present its activities and principles in a structured manner. We start from the perspective of the Praxeological Organizations of the Anthropological Theory of Didactics, using the analytical tool Organization of Teaching Method. The structure of the PI was explicit in types of task, techniques, and technological discourses. Such analysis can contribute to research and teaching activities using the method allowing the establishment of a reference to evaluate changes and adaptations in the PI.
\end{abstract}

https://orcid.org/0000-0003-2294-6879 - Licenciado em Física pela Universidade Federal do Rio Grande do Sul (UFRGS). Mestrando em Ensino de Física (UFRGS), Porto Alegre, Rio Grande do Sul, Brasil. Av. Bento Gonçalves, 9500, Instituto de Física, Agronomia, 91501-970, Porto Alegre, Rio Grande do Sul, Brasil. E-mail: felippe.percheron@ufrgs.br

2 (iD https://orcid.org/0000-0001-6612-8697 - Licenciada em Física pela Universidade Federal do Rio Grande do Sul (UFRGS). Mestranda em Ensino de Física (UFRGS), Porto Alegre, Rio Grande do Sul, Brasil. Av. Bento Gonçalves, 9500, Instituto de Física, Agronomia, 91501-970, Porto Alegre, Rio Grande do Sul, Brasil. E-mail: anaameliapetter@gmail.com

3 iD https://orcid.org/0000-0002-6958-8274 - Doutor em Ensino de Física pela Universidade Federal do Rio Grande do Sul (UFRGS). Professor do Instituto de Matemática, Estatísticas e Física da Universidade Federal do Rio Grande (FURG), Santo Antônio da Patrulha, Rio Grande do Sul, Brasil. Barão do Cahy, 125, Cidade alta, 959000-000, Santo Antônio da Patrulha, Rio Grande do Sul, Brasil. E-mail: tobiasespinosa@furg.br

4 (iD http://orcid.org/0000-0002-3729-0895 - Doutor em Ciências pela Universidade Federal do Rio Grande do Sul (UFRGS). Professor do Instituto de Física (UFRGS), Porto Alegre, Rio Grande do Sul, Brasil. Av. Bento Gonçalves, 9500, Instituto de Física, Agronomia, 91501-970, Porto Alegre, Rio Grande do Sul, Brasil.E-mail: ives@if.ufrgs.br 
Keywords: Peer Instruction; Praxeological Organization; Organization of Teaching Method; Anthropological Theory of the Didactic.

\section{Introdução}

De modo geral, a alteração da metodologia de ensino empregada em sala de aula costuma ser uma das primeiras ações cogitadas quando se pensa em melhorar a qualidade do aprendizado discente. Mesmo que essa alteração não seja o fator decisivo para alcançar tal resultado, ela costuma estar, em boa medida, no escopo daquilo que muitos docentes têm liberdade para empreender. Dentre as diversas possibilidades, têm ganho destaque nas últimas décadas a adoção de metodologias e métodos ativos de ensino, tais como Peer Instruction (MAZUR, 1997, 2015), Project-Based Learning (BENDER, 2014), Problem-Based Learning (BARROWS; TAMBLYN, 1980), Just-in-Time Teaching (NOVAK; GAVRIN; CHRISTIAN, 1999) $e$ Team-Based Learning (MICHAELSEN; KNIGHT; FINK, 2004).

Dentre esses, o Peer Instruction (PI) é um dos métodos que possui maior reconhecimento, seja pela promoção de um engajamento ativo dos estudantes, como também por intensificar a aprendizagem conceitual e desenvolver habilidades sociais e cognitivas (MÜLLER et al., 2017), sob uma estrutura menos expositiva. Elaborado pelo professor Eric Mazur, da Universidade de Harvard, o PI é um método ativo de ensino cujo principal objetivo é promover a aprendizagem através da interação entre os alunos durante as aulas (ARAUJO; MAZUR, 2013). O método visa direcionar as atenções (dos alunos e professores) em conceitos fundamentais, apresentando uma estrutura que promove práticas argumentativas entre os próprios alunos, conduzindo a novos conhecimentos (TULLIS; GOLDSTONE, 2020).

O PI, também, apresenta impactos positivos na aprendizagem conceitual, na habilidade de resolução de problemas e no desempenho acadêmico (MÜLLER et al., 2017). Além disso, as atividades indicadas pelo método podem ser incorporadas às atividades de ensino usuais, sem necessidade de grandes modificações curriculares para sua implementação. Tais aspectos o colocam como o método ativo mais usado por professores de Física de nível universitário (HENDERSON; DANCY, 2009; TULLIS; GOLDSTONE, 2020). Contudo, conforme apontado por alguns estudos (DANCY; HENDERSON; TURPEN, 2016; HENDERSON, 2005), as tentativas de aplicá-lo nos mais diversos contextos de ensino, bem diferentes daquele para o qual o método foi proposto, podem levar a modificações que desconsiderem seus princípios pedagógicos e gerem frustrações com os resultados, tendo em vista sua descaracterização.

Frente a esses problemas, entendemos como oportuno apresentar a pesquisadores e professores adotantes do $\mathrm{PI}$ uma proposta de detalhamento de seus elementos práticos e teóricos de forma integrada. Isso pode ser particularmente útil para tomar decisões sobre o que mudar ou não ao realizar alterações para viabilizar o método em determinado contexto de ensino. Essa proposta assume a forma de uma Organização Praxeológica (OP) (CHEVALLARD, 1999), a exemplo da Organização do Método de Ensino (OME) proposta por Espinosa, Araujo e Veit (2019) para o Team-Based Learning (TBL). 


\section{Peer Instruction: o método e a literatura}

Um dos principais objetivos do Peer Instruction (PI), ou Instrução pelos Colegas (IpC), é preconizar a interação e o debate entre estudantes, concedendo a eles um papel ativo no processo de aprendizagem. Nesse sentido, um dos principais pilares do PI é que, ao discutir um tópico com um colega, um aluno pode aprender com o outro, promovendo através desse diálogo uma aprendizagem conceitual.

O PI sofreu transformações ao longo do tempo (ARAUJO; MAZUR, 2013; MAZUR, 1997, 2015; MAZUR; WATKINS, 2010), e no presente artigo partimos de uma versão do PI na qual ele é articulado com o Just-in-Time Teaching (JiTT) (ARAUJO; MAZUR, 2013). Em poucas palavras, esses métodos combinados iniciam com a realização de uma tarefa prévia à discussão do conteúdo em classe, objetivando introduzir, com uma abordagem mais geral, o que será estudado ao longo da aula. Essa tarefa, originalmente chamada de tarefa de leitura, é constituída por algum material a ser estudado e disponibilizada pelo professor (ARAUJO; MAZUR, 2013), como um trecho de um livro, um vídeo ou alguma simulação, acompanhada de questões que guiem o aluno nesse exercício. Por esse motivo, e a fim de evitar confusões, chamaremos a tarefa de leitura de Tarefa de Preparação Prévia (TPP). O retorno dessas respostas à TPP possibilita que o professor adapte as aulas às principais dúvidas de cada turma e dedique o tempo em sala para discussões e engajamento ativo dos alunos.

Em sala de aula, o professor apresenta curtas exposições orais sobre os conceitos-chave, considerando o que o aluno já sabe, e intercalando-as com a apresentação de Testes Conceituais (TCs). Esses testes se constituem em questões, usualmente do tipo múltipla escolha, construídas para avaliar o entendimento conceitual alcançado pelos alunos. Conforme salientam Araujo e Mazur (2013, p. 373), os testes conceituais "devem requerer reflexões sobre os conceitos de modo que os estudantes não consigam respondê-las meramente substituindo valores em fórmulas, ou simplesmente usando a memória sobre algo que foi discutido anteriormente". Após propor cada TC, o professor solicita aos estudantes que individualmente escolham uma alternativa, pensem em uma justificativa capaz de convencer um colega do porquê sua escolha é correta, e se comprometam com a resposta escolhida a partir de uma votação individual.

A partir da distribuição das respostas, o docente pode prosseguir a aula de três maneiras, de acordo com a frequência de acertos: maior que $70 \%$; entre $30 \%$ e $70 \%$; e menor que $30 \%$. As recomendações para os cenários ( $>70 \%$ e $>30 \%$ ) são exploradas na Seção 4 , em que apresentamos a OME do $\mathrm{PI}$, detalhando cada atividade prevista no método. O melhor aproveitamento do método acontece quando a quantidade de acertos ficar entre $30 \%$ e $70 \%$. Nesse caso é recomendado ao professor organizar os alunos em pequenos grupos e solicitar que convençam um colega, que tenha escolhido uma resposta diferente da sua. Após essa discussão, outra votação individual é realizada, e o professor discute a questão com a turma. Dessa forma, um estudante pode aprender com o outro e a partir da argumentação promover sua compreensão conceitual que é fundamental para aprendizagem em Física. O docente pode optar por prosseguir a aula realizando outros TCs do mesmo tópico ou reiniciar o processo com uma breve exposição dialogada de um novo conceito. Sintetizamos as atividades desse método utilizando uma ilustração produzida por Araujo e Mazur (2013), apresentada na Figura 1. 


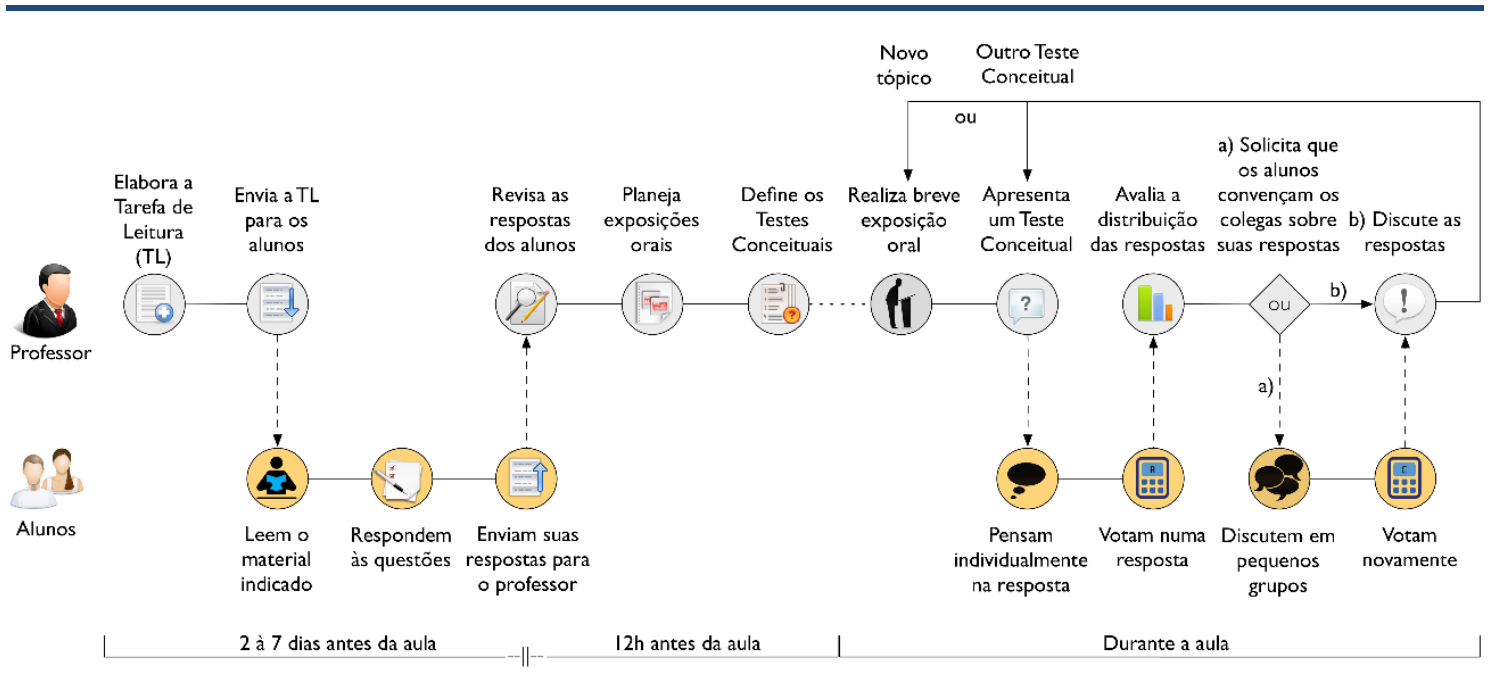

Figura 1 - Diagrama do Peer Instruction combinado com Just-in-Time Teaching. (Fonte: Adaptado de Araujo e Mazur, 2013, p. 374)

Em recente revisão da literatura, Müller et al. (2017) identificaram que as pesquisas sobre o PI ocorrem predominantemente na educação superior ( $n=57$ em universidades), na América do Norte $(n=42)$, na área STEM ( $n=59)$, com destaque para a Física $(n=31)$ dentro dessa grande área (i.e., na sua disciplina de origem). Os resultados encontrados (Ibid.) indicam que a adoção do PI gera benefícios para a aprendizagem, como o desenvolvimento de crenças e atitudes positivas em relação ao método e incremento na aprendizagem conceitual, sem distinções de etnia e gênero.

$\mathrm{Na}$ busca por resultados instrucionais de implementação do $\mathrm{PI}$, os mesmos autores evidenciaram que nem todas as pesquisas analisadas utilizaram o método na sua forma original (Ibid.). Essa variedade de modificações realizadas, durante a implementação, mostra que o PI é facilmente adaptável aos objetivos de ensino que diferentes contextos possuem. No entanto, salientamos aqui a importância de compreender os princípios pedagógicos que sustentam cada etapa do método, para que mudanças que o descaracterizem não sejam realizadas.

O conhecimento das ações esperadas, das técnicas para realizar essas ações e dos princípios pedagógicos que sustentam o método representam pontos essenciais para a adoção do PI. Nesse sentido, o nosso estudo visa contribuir evidenciando os tipos de tarefa, as técnicas e tecnologias de referência do método, possibilitando uma adoção consciente do método e facilitando a articulação desse método com referenciais teóricos.

O estudo de Turpen, Dancy e Henderson (2016) já apresenta nove elementos que compõem o PI para analisar sua adoção, o que vai ao encontro da nossa proposta de fazer uma OP do método. A diferença está na fundamentação da categorização. No artigo de Turpen e colaboradores (Ibid.), apenas tipos de tarefa são apresentados. Na OME explicitaremos o método evidenciando as técnicas e tecnologias que sustentam cada tipo de tarefa apresentado. Tal proposta possibilita que os futuros adotantes compreendam as etapas do $\mathrm{Pl}$ e os princípios que sustentam o método. Além disso, "a utilização de uma organização praxeológica tem potencial de explicitar problemas de origem didática" (ESPINOSA, 2019, p. 49). Por fim, essa proposta de OME do PI também evita que outros professores acabem insatisfeitos e frustrados 
com os resultados obtidos com a implementação do PI devido à falta de informações sobre a inovação (HENDERSON, 2005).

\section{Referencial teórico e metodológico}

A Teoria Antropológica do Didático (TAD), desenvolvida principalmente pelo matemático e didata francês Yves Chevallard (1999, 2019), situa o estudo em um conjunto de atividades humanas regularmente realizadas, buscando compreender as práticas inerentes a isso sob uma perspectiva institucional. De certo modo, esse enfoque visa propor respostas a críticas tecidas à Teoria da Transposição Didática, destacando que não se compreende a transposição didática como um mero processo de transferência de conhecimentos entre instituições.

Como princípio estrutural à TAD, Chevallard (2019) entende que o fenômeno do didático (i.e., do estudo), assim como toda atividade humana, pode ser compreendido através do modelo de Organização Praxeológica (OP). Também chamadas de praxeologias, o modelo das OPs é formado por blocos de elementos que descrevem práticas (praxis) e conhecimentos (logos). 0 bloco da praxis, do "saber-fazer", é constituído por tipos de tarefa $(\mathrm{T})$ e técnicas $(\tau)$, e o bloco de logos, do "saber", é composto por tecnologias $(\theta)$ e teorias $(\Theta)$.

Tipos de tarefa são ações a serem realizadas, como "subir uma escada, [...] calcular o valor de uma função em um ponto" (CHEVALLARD, 1999, p. 222). Uma técnica é uma determinada forma de resolver $\mathrm{T}$. Ou seja, podem existir diversas técnicas para um mesmo tipo de tarefa, e essas podem promover resultados melhores umas em relação às outras. Desse modo, "uma técnica não é necessariamente de natureza algorítmica ou quase algorítmica. Axiomatizar um campo das matemáticas, pintar uma paisagem, formar uma família são tipos de tarefa para os quais não há necessariamente uma técnica algorítmica" (CHEVALLARD, 1999, p. 223). Para uma técnica, $\tau$, existir em uma instituição, é necessário que ela esteja amparada em alguma tecnologia, $\theta$, que se trata de um discurso racional institucionalmente aceito que seja capaz de justificar, explicar e gerar técnicas, as tornando "inteligíveis aos usuários" (CHEVALLARD, 2019, p. 89). As afirmações de um discurso tecnológico podem necessitar de um nível maior de racionalização. Nesse sentido, uma teoria, $\Theta$, representa um progresso teórico de uma tecnologia, apresentando um "nível superior de justificação-explicação-produção que retoma, em relação à tecnologia, o papel que essa última tem a respeito da técnica" (CHEVALLARD, 1999, p. 225).

Uma praxeologia, portanto, é o conjunto $[\mathrm{T} / \tau / \theta / \Theta]$ para uma certa atividade que pode ser criada em uma determinada instituição, sendo sua concepção influenciada por características desse contexto de produção. De acordo com Winsløw (2011), as OPs estão sujeitas a modificações quando são transpostas entre contextos diferentes, posto que condições e restrições de uma nova instituição podem impor transformações. Por exemplo, uma praxeologia pode ser aceita, ou recusada, em uma instituição por conter discursos tecnológicos e teóricos que justifiquem, ou contraponham, práticas que já estejam institucionalizadas.

Partindo desses pressupostos, Espinosa, Araujo e Veit (2019) discutem as OPs como uma ferramenta analítica para a análise de métodos de ensino, os concebendo como conhecimentos social e historicamente legitimados e passíveis de modificações quando transitam entre as 
instituições. Nesse sentido, os autores sustentam que "assim como podemos estudar as organizações matemáticas e físicas [i.e., OPs para disciplinas], podemos estudar a Organização do Método de Ensino" (ESPINOSA; ARAUJO; VEIT, 2019, p. 381). Essa Organização do Método de Ensino (OME) se configura segundo a estrutura das OPs, propiciando analisar e descrever como as atividades propostas em um método de ensino estão distribuídas em práticas e em respectivas justificativas.

Para exemplificar sua proposta, os autores propõem uma OME (i.e., uma praxeologia) de referência para o método ativo de ensino Team-Based Learning (TBL). O TBL preconiza melhorar a compreensão do conteúdo e desenvolver equipes de aprendizagem, propondo uma organização das aulas em módulos. Esses módulos estão distribuídos em fases de preparação individual e em equipe (orientada por leituras prévias acerca do conteúdo e respostas a algumas perguntas sobre essa leitura), e aplicação também individual e em equipe (constituída por resolução de problemas de aplicação dos conceitos estudados na preparação, compartilhando em aula as suas soluções com as demais equipes).

Como resultado geral, os autores entendem que uma OME sob a forma de uma OP se constitui como um saber de referência. Além de auxiliar na identificação de transformações, essa OME de referência pode servir para orientar as transformações que ocorrem ao implementar um método de ensino, uma vez que ao destacar os elementos de um método possibilita-se preservar os seus princípios pedagógicos (Ibid.). Nesse sentido, evidenciar a estrutura dos métodos de ensino contribui para que eles não sejam concebidos como simplesmente um conjunto de técnicas, uma vez que esse entendimento pode complicar "o diálogo entre pesquisa e prática, já que isso dificulta a compreensão da transformação dos métodos de ensino quando transitam interinstitucionalmente" (ESPINOSA; ARAUJO; VEIT, 2019, p. 383). Isso é particularmente importante para o caso dos métodos ativos de ensino, como o TBL e o próprio Peer Instruction (PI), posto que as investigações sobre esses métodos "apontam que os professores raramente põem em prática as inovações na forma como são prescritas por seus criadores e, normalmente, as modificam reduzindo suas potencialidades" (ESPINOSA; ARAUJO; VEIT, 2019, p. 383).

Ainda, esses autores, com base na estrutura de uma OP, propuseram uma ferramenta analítica que apresenta caminhos metodológicos possíveis para analisar e criar métodos de ensino (discutida na Seção seguinte). Assim como no estudo proposto com o TBL (Ibid.), neste artigo nos focamos em uma análise de um método de ensino - o PI - com êxitos, em virtude de sua implementação, mas efetivamente pouco adotados e sujeito a muitas modificações (TULLIS; GOLDSTONE, 2020).

Portanto, métodos de ensino, de uma forma geral, não se resumem unicamente a um aglomerado de técnicas, contendo conhecimentos que são indispensáveis às suas existências. Nesse sentido, o uso de um modelo para estruturá-los pode proporcionar o entendimento necessário sobre suas especificidades, podendo facilitar a identificação de modificações, e até mesmo orientá-las, para a implementação em diferentes situações. Desse modo, nosso estudo se apoia na perspectiva da TAD, partindo das construções elaboradas por Espinosa, Araujo e Veit (2019). 


\section{Uma Organização do Método de Ensino Peer Instruction}

Para a construção de uma Organização do Método de Ensino (OME) de referência para o Peer Instruction, buscamos identificar os seus principais tipos de tarefa, técnicas e discursos tecnológicos para o topos $^{1}$ do professor, de acordo com as descrições desse método ativo presentes em Araujo e Mazur (2013) e Mazur (2015). Para tanto, utilizamos a ferramenta analítica para estruturação de métodos de ensino em termos de praxeologias proposta por Espinosa, Araujo e Veit (2019) (Quadro 1), obtendo os dados a partir de leituras integrais desses materiais de referência. A categorização dos dados, em termos de elementos da praxeologia, foi feita a partir das orientações e questões guia expostas no Quadro 1.

Quadro 1 - Ferramenta analítica para identificar a estrutura de métodos de ensino em termos de Tipos de Tarefa, Técnicas, Tecnologias e Teorias (adaptado de Espinosa, Araujo e Veit, 2019).

\begin{tabular}{|c|c|c|c|}
\hline Tipos de Tarefa (T) & Técnica $(\tau)$ & Tecnologia $(\theta)$ & Teoria (Ө) \\
\hline $\begin{array}{l}\text { São agrupadas nessa } \\
\text { categoria as declarações } \\
\text { relacionadas às ações } \\
\text { atribuídas ao professor } \\
\text { e aos alunos para o } \\
\text { funcionamento de } \\
\text { ensino }\end{array}$ & $\begin{array}{c}\text { Argumentos que } \\
\text { expressam os meios } \\
\text { que o professor e os } \\
\text { alunos podem seguir } \\
\text { para realizar as ações } \\
\text { propostas pelo método } \\
\text { de ensino são alocadas } \\
\text { nessa categoria }\end{array}$ & $\begin{array}{l}\text { Discursos racionais que } \\
\text { justificam, explicam ou } \\
\text { criam as estratégias } \\
\text { adotadas para a } \\
\text { aplicação do método } \\
\text { são colocadas nessa } \\
\text { categoria }\end{array}$ & $\begin{array}{l}\text { Argumentos racionais } \\
\text { que justificam, } \\
\text { explicam ou criam } \\
\text { discursos tecnológicos } \\
(\theta)\end{array}$ \\
\hline $\begin{array}{l}\text { Quais são, do ponto de } \\
\text { vista do professor, as } \\
\text { ações requeridas para a } \\
\text { aplicação do método? }\end{array}$ & $\begin{array}{l}\text { Como o professor e os } \\
\text { alunos devem realizar } \\
\text { as ações propostas pelo } \\
\text { método de ensino? }\end{array}$ & $\begin{array}{c}\text { Por que são propostas } \\
\text { tais estratégias para a } \\
\text { aplicação do método de } \\
\text { ensino? }\end{array}$ & $\begin{array}{l}\text { Por que os discursos } \\
\text { que legitimam as } \\
\text { estratégias do método } \\
\text { de ensino são } \\
\text { proferidos? Em que } \\
\text { estão } \\
\text { fundamentados? }\end{array}$ \\
\hline
\end{tabular}

No Quadro 2 exemplificamos o processo analítico realizado em um dos textos que compõe o corpus de análise. Nele, apresentamos alguns recortes provenientes do artigo de Araujo e Mazur (2013) e uma síntese de nossas interpretações para cada elemento praxeológico. Cabe salientar que as interpretações não levam em consideração apenas os trechos selecionados; elas consideram uma visão ampla do método, adquirida a partir do sentido que atribuímos à leitura completa e atenta das obras. Por isso, alguns elementos da praxeologia não são possíveis de serem representados apenas por trechos isolados. Por exemplo, no fragmento apresentado para a técnica $\tau_{1}$, os autores mencionam que a tarefa de preparação é composta por um texto e algumas questões. No entanto, entendemos, ao longo da análise, que o texto é

${ }^{1}$ Topos se refere ao papel (ou lugar) de um determinado ator em uma atividade humana. No caso das Organizações de Método de Ensino, há, pelo menos, dois topos a serem considerados, o do professor e o do aluno. Neste artigo, frente ao objetivo estabelecido, optamos por construir a praxeologia do PI referente ao topos do professor. 
uma proposta de ferramenta para a exposição do conteúdo, podendo ser substituído por um vídeo ou outro material de apoio.

Quadro 2 - Exemplo de categorização e interpretação da organização do método Peer Instruction, para o topos do professor.

\begin{tabular}{|c|c|c|}
\hline $\begin{array}{l}\text { Pergunta } \\
\text { orientadora }\end{array}$ & Fragmentos da obra & Interpretação \\
\hline $\begin{array}{l}\text { Quais são as } \\
\text { ações requeridas } \\
\text { do professor para } \\
\text { a aplicação do } \\
\text { método? }\end{array}$ & $\begin{array}{l}\text { "De modo geral, o IpC [Peer Instruction] pode ser descrito } \\
\text { como um método de ensino baseado no estudo prévio de } \\
\text { materiais disponibilizados pelo professor e apresentação } \\
\text { de questões conceituais, em sala de aula, para os alunos } \\
\text { discutirem entre si." (ARAUJO; MAZUR, 2013, p. 367) }\end{array}$ & $\begin{array}{l}\mathrm{T}_{1} \text { - Possibilitar o } \\
\text { preparo prévio dos } \\
\text { estudantes. }\end{array}$ \\
\hline $\begin{array}{l}\text { Como o professor } \\
\text { deve realizar as } \\
\text { ações propostas } \\
\text { pelo método? }\end{array}$ & $\begin{array}{l}\text { "Essa etapa é conhecida como 'exercício de aquecimento' } \\
\text { (WarmUp exercise) e se constitui em uma atividade de } \\
\text { preparação prévia à aula. Nela o professor solicita que os } \\
\text { alunos leiam materiais de apoio [...] e logo após } \\
\text { respondam [...] algumas questões [...]" (ARAUJO; MAZUR, } \\
2013, \text { p. 371). "[...] o professor envia a TL [Tarefa de } \\
\text { Leitura] com certa antecedência (dois a sete dias antes da } \\
\text { aula) para os estudantes." (ARAUJO; MAZUR, 2013, p. } \\
\text { 374) }\end{array}$ & $\begin{array}{l}\tau_{1} \text { - Disponibilizar aos } \\
\text { alunos uma Tarefa de } \\
\text { Preparação Prévia } \\
\text { (TPP), composta por } \\
\text { um material de apoio } \\
\text { (e.g., texto ou vídeo) } \\
\text { e cerca de três } \\
\text { questões, entre } 2 \text { e } 7 \\
\text { dias antes da aula. }\end{array}$ \\
\hline $\begin{array}{l}\text { Por que são } \\
\text { propostas tais } \\
\text { estratégias para a } \\
\text { aplicação do } \\
\text { método de } \\
\text { ensino? }\end{array}$ & $\begin{array}{l}\text { "Os exercícios de aquecimento têm como objetivos } \\
\text { promover o pensamento crítico sobre o texto lido, } \\
\text { introduzir o que será trabalhado em aula e estimular os } \\
\text { alunos a elaborarem argumentações, expressas em suas } \\
\text { próprias palavras, para embasar suas respostas." } \\
\text { (ARAUJO; MAZUR, 2013, p. 371) } \\
\text { "[...] um dos objetivos centrais das Tarefas de Leitura está } \\
\text { associado à criação do hábito de estudo por parte dos } \\
\text { alunos." (ARAUJO; MAZUR, 2013, p. 379) }\end{array}$ & $\begin{array}{l}\theta_{\tau_{1}}-\text { A TPP, além de } \\
\text { valorizar o tempo em } \\
\text { sala de aula, promove } \\
\text { o pensamento crítico } \\
\text { e a habilidade de } \\
\text { argumentação dos } \\
\text { estudantes. Ademais, } \\
\text { estimula a criação do } \\
\text { hábito de estudo. }\end{array}$ \\
\hline
\end{tabular}

No material analisado, não identificamos elementos teóricos explícitos para a OME de referência, isto é, não foram encontrados discursos que justifiquem, expliquem ou gerem as tecnologias identificadas. Nesse sentido, fica evidente que o método não conta com uma teoria de aprendizagem explícita que o sustente. $O$ desenvolvimento ateórico, de caráter pragmático, é "característico dos métodos de ensino norte-americanos. Nesse sentido, é difícil encontrar teorias explícitas que justifiquem as tecnologias. O desenvolvimento se dá na prática, e os avanços e modificações são realizados a partir de resultados de investigação empírica" (ESPINOSA; ARAUJO; VEIT, 2019, p. 386).

$\mathrm{Na}$ sequência, discutimos em detalhes a OME de referência proposta para o $\mathrm{PI}$, considerando o topos do professor. Dividimos a apresentação da OME em tipos de tarefa, técnicas e tecnologias a serem articuladas antes (Quadro 3) e durante a aula (Quadro 4). Nos Quadros 3 e 4 são apresentadas versões simplificadas da OME. Descrições detalhadas, com aspectos específicos e complementares dos elementos da praxeologia, são discutidas ao longo do texto. Em particular para as Tecnologias $(\theta)$, os itens elencados não correspondem a todos 
relacionados com a justificativa das respectivas técnicas, mas aqueles que julgamos mais salientes. Nossa análise parte do pressuposto de que os conteúdos a serem ensinados, e seus respectivos conceitos-chave, já foram definidos em planejamento anterior da unidade de ensino.

Quadro 3 - Organização do Método de Ensino de referência do PI referente ao momento extraclasse, no topos do professor.

\begin{tabular}{|c|c|c|}
\hline Tipo de Tarefa (T) & Técnica $(\tau)$ & Tecnologia $(\theta)$ \\
\hline $\begin{array}{l}\mathrm{T}_{1} \text { - Possibilitar o } \\
\text { preparo prévio } \\
\text { dos estudantes. }\end{array}$ & $\begin{array}{l}\tau_{1} \text { - Disponibilizar aos alunos uma } \\
\text { Tarefa de Preparação Prévia (TPP), } \\
\text { composta por um material de apoio } \\
\text { (e.g., texto ou vídeo) e cerca de três } \\
\text { questões, entre } 2 \text { e } 7 \text { dias antes da } \\
\text { aula. }\end{array}$ & $\begin{array}{l}\theta_{\tau_{1}} \text { - A TPP, além de valorizar o tempo em } \\
\text { sala de aula, promove o pensamento crítico } \\
\text { e a habilidade de argumentação dos } \\
\text { estudantes. Ademais, estimula a criação do } \\
\text { hábito de estudo. }\end{array}$ \\
\hline $\begin{array}{l}\mathrm{T}_{2} \text { - Planejar } \\
\text { explicações sobre } \\
\text { os conceitos- } \\
\text { chave. }\end{array}$ & $\begin{array}{l}\tau_{2} \text { - Organizar breves exposições } \\
\text { orais (menos de } 15 \text { minutos) } \\
\text { orientadas pelas dificuldades e } \\
\text { dúvidas identificadas na TPP. }\end{array}$ & $\begin{array}{l}\theta_{\tau_{2}} \text { - O planejamento das aulas a partir das } \\
\text { respostas coletadas na TPP permite que a } \\
\text { abordagem do conteúdo seja ajustada às } \\
\text { dificuldades e interesses da turma. Além } \\
\text { disso, exposições breves liberam tempo em } \\
\text { sala de aula, que pode ser destinado ao } \\
\text { estudo ativo dos alunos. }\end{array}$ \\
\hline $\begin{array}{l}\mathrm{T}_{3} \text { - Planejar } \\
\text { formas de avaliar } \\
\text { a compreensão } \\
\text { dos alunos sobre } \\
\text { os conceitos- } \\
\text { chave. }\end{array}$ & $\begin{array}{l}\tau_{3} \text { - Revisar as respostas dos alunos } \\
\text { à TPP e, a partir das principais } \\
\text { dificuldades e dúvidas identificadas, } \\
\text { elaborar ou buscar questões } \\
\text { conceituais (com foco em um único } \\
\text { conceito). }\end{array}$ & $\begin{array}{l}\theta_{\tau_{3}}-\text { O mapeamento daquilo que os alunos } \\
\text { já sabem, suas dificuldades e dúvidas, deve } \\
\text { orientar ações de ensino que possibilitem os } \\
\text { alunos aprenderem uns com os outros, além } \\
\text { de torná-los conscientes sobre o próprio } \\
\text { nível de entendimento conceitual ora } \\
\text { alcançado. }\end{array}$ \\
\hline
\end{tabular}

A implementação do PI começa com o planejamento das aulas, descrito pelos tipos de tarefa $\mathrm{T}_{1}, \mathrm{~T}_{2}$ e $\mathrm{T}_{3}$. Para que os alunos se preparem para discutir de determinado tópico $\left(\mathrm{T}_{1}\right)$, o professor disponibiliza a eles uma Tarefa de Preparação Prévia (TPP) $\left(\tau_{1}\right)$. A TPP consiste em um material a ser estudado que sirva para introduzir o tópico da aula, como um trecho de um livro, um vídeo ou alguma simulação, acompanhada de aproximadamente três questões que guiem o aluno nesse estudo. Sugere-se que duas dessas questões versem sobre os conceitos abordados, e pelo menos uma seja do tipo dissertativa. A terceira questão deve possibilitar ao docente avaliar o entendimento e o engajamento do estudante na atividade. Isso pode ser feito pedindo ao estudante que explicite suas dúvidas relacionadas ao estudo, ou que exponha as partes do tópico estudado que the despertaram mais interesse. É recomendável que o professor elabore e disponibilize aos estudantes a TPP de dois a sete dias antes da aula, solicitando o envio das respostas em até 12 horas antes da aula. A avaliação dessa atividade é a partir do empenho e engajamento apresentado nas respostas.

A introdução do conteúdo com a TPP antes de discuti-lo em sala de aula, e guiado por algumas questões, promove reflexões sobre os conceitos, respeita o ritmo de aprendizagem de 
cada estudante e valoriza o tempo para discussões entre os alunos durante a aula $\left(\theta_{\tau_{1}}\right)$. Esse discurso tecnológico também sustenta que, ao se engajar nas atividades prévias, o estudante pode desenvolver o pensamento crítico e habilidades de argumentação, além de poder identificar as próprias dificuldades na compreensão do conteúdo abordado na TPP, direcionando e se responsabilizando pela própria aprendizagem. Esses fatores contribuem para o desenvolvimento de hábitos de estudo por parte dos estudantes. Ainda em $\theta_{\tau_{1}}$, temos que a avaliação das respostas à TPP em termos de raciocínio demonstrado e de empenho, sem punições, incentiva a tentativa de respostas, diminui a inibição ao erro e promove a participação dos alunos nas atividades.

De posse das respostas dos alunos à TPP, o professor dá continuidade ao delineamento das atividades a serem desenvolvidas durante a aula. Nesse sentido, é esperado que o professor planeje explicações sobre os conceitos-chave a serem apresentados durante a aula $\left(\mathrm{T}_{2}\right)$. Para isso, o professor organiza breves exposições orais (menos de 15 minutos), orientadas pelas principais dificuldades e dúvidas detectadas na TPP, abordando um único conceito a cada exposição $\left(\tau_{2}\right)$. Recomenda-se exemplificar tais dúvidas com recortes das respostas, sem identificar o respondente, assim como incorporar a essas exposições recursos que melhor se adequem às demandas dos estudantes (e.g., demonstração experimental, simulação computacional, exposição de slides).

No discurso tecnológico que justifica $\tau_{2}\left(\theta_{\tau_{2}}\right)$ é defendido que o planejamento das aulas a partir da análise das respostas dos alunos da TPP permite que a abordagem do conteúdo seja ajustada às dificuldades e interesses da turma e que as dúvidas remanescentes do estudo sejam esclarecidas. Ademais, sanar as dificuldades dos alunos, respondendo às questões por eles propostas, faz com que se sintam valorizados e engajados nas discussões. A não identificação de quem elaborou uma resposta selecionada garante que os estudantes se sintam seguros para participar das atividades, sem risco de exposição desnecessária. A brevidade das exposições é justificada pelo argumento, subjacente a diferentes técnicas do $\mathrm{Pl}$, de que o tempo em sala de aula deve ser valorizado com atividades que promovam o engajamento ativo dos estudantes em sala de aula.

Para finalizar a atividade de planejamento das aulas, o professor prepara formas de avaliar a compreensão dos alunos a respeito dos conceitos-chave estudados $\left(\mathrm{T}_{3}\right)$. A técnica proposta para resolver $\mathrm{T}_{3}$ é elaborar ou selecionar Testes Conceituais (TCs) que estejam relacionados às principais dificuldades e dúvidas identificadas pelo professor nas respostas dos alunos à TPP. Esses TCs são questões conceituais, usualmente de múltipla escolha, direcionadas a um único conceito, que envolvam possíveis concepções alternativas, sem linguagem ambígua, com alternativas adequadas e com uma única resposta correta. Para tanto, o professor revisa as respostas dos alunos à TPP e, a partir das principais dificuldades e dúvidas identificadas, elabora ou busca esses TCs $\left(\tau_{3}\right)$, de modo a problematizar o conceito apresentado em cada exposição oral.

Assim como em $\theta_{\tau_{2}}$, a busca por TCs que envolvam as dificuldades apresentadas pelos estudantes na TPP se justifica pela adequação do nível das questões às especificidades da turma, possibilitando melhores condições para que os alunos aprendam uns com os outros $\left(\theta_{\tau_{3}}\right)$. 
Considera-se em ambos os casos $\left(\theta_{\tau_{2}}\right.$ e $\left.\theta_{\tau_{3}}\right)$ a importância dos conhecimentos prévios do estudante para a construção da aprendizagem. $\mathrm{Em} \theta_{\tau_{3}}$ ainda temos que questões de múltipla escolha, direcionadas a um único conceito e que envolvam possíveis concepções alternativas, podem promover, além da compreensão dos conceitos, o comprometimento dos alunos com uma resposta, propiciando que os estudantes busquem argumentos para defendê-la. Esse formato de questão pode ampliar as possibilidades de discussões em sala de aula. Além disso, permite o diagnóstico do professor acerca do nível de compreensão da turma sobre um conceito particular, o que facilita o direcionamento das ações didáticas subsequentes.

A seguir, apresentamos uma OME para as atividades preconizadas pelo $\mathrm{PI}$ a serem realizadas durante a aula e, de forma resumida, as indicamos no Quadro 4. A numeração dos elementos praxeológicos segue a sequência estabelecida no quadro anterior.

Durante o período destinado à aula, o professor deve explicar os conceitos-chave aos alunos $\left(\mathrm{T}_{4}\right)$. Para tanto, é recomendado realizar breves exposições orais focada em um único conceito cada. Nelas, o professor pode expor, de maneira organizada e lógica, as respostas às dúvidas dos alunos identificadas na TPP, oportunizando que dialoguem com o professor $\left(\tau_{4}\right)$. A técnica $\tau_{4}$ promove um feedback ao aluno durante a aula que o auxilia a melhor compreender o conteúdo e se engajar no processo de ensino-aprendizagem $\left(\theta_{\tau_{4}}\right)$. Além disso, com a realização da breve exposição, conforme planejada em $\mathrm{T}_{2}$ e $\tau_{2}$, é possível que o tempo em aula seja melhor aproveitado para o engajamento ativo dos alunos, possibilitando mais momentos de diálogo entre professor e alunos.

Após cada exposição oral breve, cabe ao professor promover oportunidades de os alunos mobilizarem os conceitos-chave estudados e realizarem uma autoavaliação acerca da própria compreensão $\left(\mathrm{T}_{5}\right)$. Para isso, o docente apresenta à turma um TC sobre o conceito em estudo, selecionado ou elaborado ao aplicar a técnica $\tau_{3}$.

Depois de expor o TC aos alunos, o professor solicita a eles que $\left(\tau_{5}\right)$ : i) pensem individualmente em uma resposta (sem debaterem sobre o TC uns com os outros); ii) elaborem uma justificativa pela escolha dessa resposta, e que sirva para convencer um colega que tenha escolhido uma alternativa diferente; e iii) votem na alternativa escolhida utilizando um sistema de votação.

Além disso, os TCs relacionados a cada conceito devem ser intercalados com as exposições, não apenas alocados ao final da aula. $O$ registro das respostas pode ser realizado de diferentes formas, a saber: cartões de resposta (Flashcards ${ }^{\circledR}$ ), dispositivos de votação eletrônica (Clickers ${ }^{\circledR}$ ), cartões com códigos detectáveis por smartphones (Plickers ${ }^{\circledR}$ ), levantando os dedos etc. (ARAUJO; MAZUR, 2013). Notemos que modificar o instrumento de votação não altera a técnica a $\tau_{5}$.

Quadro 4 - Organização do Método de Ensino de referência do PI referente ao momento em classe, no topos do professor.

\begin{tabular}{|c|c|c|}
\hline Tipo de Tarefa $(\mathrm{T})$ & Técnica $(\tau)$ & Tecnologia $(\theta)$ \\
\hline
\end{tabular}




\begin{tabular}{|c|c|c|}
\hline $\begin{array}{l}\mathrm{T}_{4}-\text { Explicar os } \\
\text { conceitos-chave } \\
\text { aos alunos. }\end{array}$ & $\begin{array}{l}\tau_{4} \text { - Realizar breves exposições orais, } \\
\text { cada uma focada em um conceito- } \\
\text { chave estudado pelos alunos na TPP, } \\
\text { respondendo às dúvidas levantadas. }\end{array}$ & $\begin{array}{l}\theta_{\tau_{4}} \text { - Explicações orientadas para o } \\
\text { esclarecimento das dúvidas discentes } \\
\text { fornecem a eles o feedback necessário } \\
\text { para que melhor compreendam os } \\
\text { conteúdos e também se engajem no } \\
\text { processo de ensino-aprendizagem ao } \\
\text { receberem atenção personalizada. }\end{array}$ \\
\hline $\begin{array}{l}\mathrm{T}_{5} \text { - Oportunizar } \\
\text { aos estudantes a } \\
\text { mobilização dos } \\
\text { conceitos-chave } \\
\text { estudados e a } \\
\text { autoavaliação da } \\
\text { compreensão. }\end{array}$ & $\begin{array}{l}\tau_{5} \text { - Apresentar um Teste Conceitual à } \\
\text { turma e solicitar que: i) pensem } \\
\text { individualmente em uma resposta; ii) } \\
\text { elaborem uma justificativa para a sua } \\
\text { escolha, capaz de convencer um colega } \\
\text { que tenha respondido de forma } \\
\text { diferente; e iii) votem na resposta que } \\
\text { julgarem correta. }\end{array}$ & $\begin{array}{l}\theta_{\tau_{5}} \text { - A aplicação de Testes Conceituais } \\
\text { permite avaliar a compreensão dos } \\
\text { conteúdos alcançada pelos alunos. } \\
\text { Além disso, a perspectiva de ter que } \\
\text { convencer os colegas sobre a correção } \\
\text { da resposta escolhida, oportuniza o } \\
\text { desenvolvimento de habilidades } \\
\text { argumentativas e o engajamento } \\
\text { cognitivo com os conteúdos em estudo. }\end{array}$ \\
\hline $\begin{array}{l}\mathrm{T}_{6}-\text { Adaptar as } \\
\text { aulas conforme a } \\
\text { compreensão dos } \\
\text { conceitos } \\
\text { demonstrada } \\
\text { pelos alunos. }\end{array}$ & $\begin{array}{l}\tau_{6} \text { - Analisar a distribuição de respostas } \\
\text { dos alunos à primeira votação } \\
\text { individual para um TC, encaminhando a } \\
\text { aula conforme um dos três cenários: i) } \\
\text { menos de } 30 \% \text { de respostas corretas, } \\
\text { recomeçar em } \mathrm{T}_{4} ; \text { ii) entre } 30 \text { e } 70 \% \text { de } \\
\text { acertos, continuar para } \mathrm{T}_{7} ; \text { iii) mais que } \\
70 \% \text { de respostas certas, passar para } \mathrm{T}_{9} \text {. }\end{array}$ & $\begin{array}{l}\theta_{\tau_{6}}-A \text { análise da distribuição das } \\
\text { respostas fornece ao docente um } \\
\text { panorama sobre a variação da } \\
\text { compreensão dos estudantes em } \\
\text { relação a determinado conceito. Os } \\
\text { melhores TCs são aqueles que obtêm } \\
\text { diferenças equilibradas no grau de } \\
\text { acertos (entre } 30 \% \text { e } 70 \% \text { ), por oferecer } \\
\text { mais chances de que um aluno possa } \\
\text { aprender com outro. }\end{array}$ \\
\hline $\begin{array}{l}\mathrm{T}_{7} \text { - Oportunizar } \\
\text { que um aluno } \\
\text { aprenda com o } \\
\text { outro. }\end{array}$ & $\begin{array}{l}\tau_{7} \text { - Em primeira votação individual das } \\
\text { respostas a um TC, solicitar que alunos } \\
\text { que escolheram respostas diferentes } \\
\text { convençam uns aos outros sobre a } \\
\text { correção da própria resposta. Após as } \\
\text { discussões, solicitar que votem } \\
\text { novamente. }\end{array}$ & $\begin{array}{lcr}\theta_{\tau_{7}}-A \text { discussão, orientada pela } \\
\text { tentativa de convencimento, mobiliza a } \\
\text { capacidade } & \text { reflexiva e } & \text { de } \\
\text { argumentação } & \text { auxiliando } & \text { na } \\
\text { compreensão } & \text { conceitual } & \text { dos } \\
\text { conteúdos. } & & \end{array}$ \\
\hline $\begin{array}{l}\mathrm{T}_{8} \text { - Adaptar } \\
\text { novamente as } \\
\text { aulas conforme a } \\
\text { compreensão dos } \\
\text { conceitos } \\
\text { demonstrada } \\
\text { pelos alunos. }\end{array}$ & $\begin{array}{l}\tau_{8} \text { - Analisar a distribuição de respostas } \\
\text { dos alunos à segunda votação } \\
\text { individual para um TC, encaminhando a } \\
\text { aula conforme um dos dois cenários: i) } \\
\text { convergência para a resposta correta, } \\
\text { passar para } \mathrm{T}_{9} ; \text { ii) distribuição de } \\
\text { respostas similar ou inferior à primeira } \\
\text { votação, recomeçar em } \mathrm{T}_{4} \text {. }\end{array}$ & $\begin{array}{l}\theta_{\tau_{8}} \text { - A análise da distribuição das } \\
\text { respostas fornece ao docente um } \\
\text { panorama sobre a variação da } \\
\text { compreensão dos estudantes em } \\
\text { relação a determinado conceito. }\end{array}$ \\
\hline $\begin{array}{l}\mathrm{T}_{9} \text { - Realizar } \\
\text { discussões finais } \\
\text { sobre os } \\
\text { conceitos-chave. }\end{array}$ & $\begin{array}{l}\tau_{9} \text { - Analisar com a turma as } \\
\text { alternativas de resposta possíveis a um } \\
\text { TC em termos da plausibilidade, do } \\
\text { raciocínio subjacente e da correção das } \\
\text { opções. }\end{array}$ & $\begin{array}{l}\theta_{\tau_{9}} \text { - Ao promover uma reflexão sobre } \\
\text { as alternativas apresentadas, e não só } \\
\text { indicar qual é a correta, o professor } \\
\text { permite que possíveis dúvidas } \\
\text { remanescentes sejam esclarecidas. }\end{array}$ \\
\hline
\end{tabular}

A aplicação de TCs, proposta em $\tau_{5}$, permite ao docente avaliar a compreensão alcançada pelos alunos em relação aos conteúdos. Além disso, a instrução que solicita aos alunos elaborarem uma justificativa, capaz de convencer os colegas de sua resposta ao TC, possibilita 
que os estudantes se engajem cognitivamente na atividade e desenvolvam habilidades argumentativas $\left(\theta_{\tau_{5}}\right)$. Nesse sentido, pedir aos alunos que simplesmente discutam com colegas que optaram por respostas diferentes pode não levar ao resultado esperado. Ainda com relação ao discurso tecnológico $\theta_{\tau_{5}}$, temos que a técnica de intercalar os TCs com as breves exposições orais objetiva evitar que nenhum aluno siga aprendendo novos conceitos sem compreender conceitos antecedentes.

Realizada a votação individual, o professor passa a adaptar a aula de acordo com a compreensão dos conceitos demonstrada pelos alunos $\left(\mathrm{T}_{6}\right)$. Para tanto, a análise da distribuição dessas respostas ao TC encaminha a continuidade da aula conforme um dos cenários expostos em $\tau_{6}$ :

i) se $30 \%$ ou menos da turma votar na resposta correta, é recomendado revisitar o conteúdo por meio de uma nova breve exposição do conceito, com uma abordagem diferente da anterior, e aplicar outro TC (i.e., recomeçar em $\mathrm{T}_{4}$ );

ii) se $70 \%$ ou mais dos alunos escolher a alternativa correta, é esperado do professor realizar uma explanação breve para concluir o estudo do conceito, e decidir se abordará o próximo conceito ou se aplicará um outro TC (passar para $\mathrm{T}_{9}$ );

iii) se entre $30 \%$ e $70 \%$ da turma escolher a resposta correta, é proposto ao professor orientar os alunos a procurarem por colegas que tenham escolhido uma alternativa diferente $e$ que então tentem convencê-los de que a sua resposta está correta (vide $\tau_{7}$ ).

A técnica $\tau_{6}$ se justifica na medida em que essa análise da distribuição das respostas fornece ao docente um panorama sobre a variação da compreensão dos estudantes acerca de um conceito, Ihe possibilitando avaliar a necessidade da realização da discussão entre os alunos nesse momento em aula $\left(\theta_{\tau_{6}}\right)$. A tecnologia $\theta_{\tau_{6}}$ ainda explica que para que a discussão seja efetiva, é necessária uma heterogenia das respostas dos alunos. Assim, oportuniza-se maior espaço para discussão e, consequentemente, maiores chances de que um aluno possa aprender com o outro. Desse modo, conforme resultados obtidos empiricamente pelo autor do método, um melhor aproveitamento dessa discussão pode ser obtido quando o percentual de acertos estiver entre $30 \%$ e $70 \%$. Cabe salientar que o discurso tecnológico que subjaz $\tau_{6}$, e caracteriza fortemente o PI, é a noção de que um aluno pode aprender com o outro.

Na situação em que o percentual de acertos dos estudantes no TC está entre $30 \%$ e $70 \%$, é esperado que o professor promova atividades em que os alunos possam aprender uns com os outros $\left(\mathrm{T}_{7}\right)$. Para isso, ele organiza pequenos grupos de discentes para discutir as respostas ao TC da primeira votação individual, solicitando que estudantes que marcaram respostas diferentes discutam suas justificativas entre si $\left(\tau_{7}\right)$. A fim de orientar essa interação, é recomendado que o professor acompanhe as discussões dos pequenos grupos, incentivando os alunos a exporem seus argumentos e levantando questionamentos que promovam a discussão. Após a interação, o professor solicita uma nova votação individual.

A tecnologia $\theta_{\tau_{7}}$ justifica $\tau_{7}$ principalmente pelo argumento de que as discussões, orientadas pela tentativa de convencimento, possibilitam que os estudantes tenham oportunidade de aprender uns com os outros ao mobilizarem suas capacidades reflexivas e 
argumentativas. Isso é facilitado uma vez que na interação eles podem aproximar o conteúdo às suas próprias linguagens. Subjaz nesse discurso tecnológico a noção, fundamental ao $\mathrm{PI}$, de que a prática da argumentação auxilia na compreensão conceitual. Do ponto de vista do professor, participar dessa discussão permite que ele a oriente e estimule, além de acompanhar os ritmos dos alunos e a evolução de seus raciocínios.

Após à segunda votação individual, cabe ao docente adaptar novamente a aula conforme a compreensão dos conceitos demonstrada pelos discentes $\left(\mathrm{T}_{8}\right)$. Para tanto, ele analisa a distribuição de respostas e encaminha a sequência da aula, como proposto em $\tau_{8}$ :

i) caso as respostas dos alunos convirjam para a resposta correta, o docente realiza uma discussão final sobre o conceito-chave $\left(\mathrm{T}_{9}\right)$;

ii) na situação em que a distribuição de respostas da turma fica similar ou inferior à primeira votação, o professor passa para uma nova tentativa de explicação do conceito, conforme $\mathrm{T}_{4}$, retomando a sequência de tipos de tarefa subsequentes.

Por fim, após a realização da segunda votação, ou quando mais de $70 \%$ dos alunos escolhe a alternativa correta na primeira votação, é aconselhado, como apontado no item i), que o professor realize uma discussão final sobre o conceito $\left(T_{9}\right)$. A técnica sugerida para isso é analisar com a turma as alternativas apresentadas, explorando a plausibilidade das respostas, o raciocínio subjacente e as correções das opções $\left(\tau_{9}\right)$. O professor pode perguntar se alguns estudantes, que tenham escolhido a alternativa correta, gostariam de expor os raciocínios que os levaram à determinada resposta. Ao fazer isso, ele possibilita que dúvidas remanescentes em relação ao conceito abordado sejam esclarecidas $\left(\theta_{\tau_{9}}\right)$. No discurso $\theta_{\tau_{9}}$ também é sustentado que promover uma maior participação dos alunos valoriza o tempo em sala de aula, destinando-o ao engajamento ativo do aluno e não à contínua exposição do professor.

Em linhas gerais, a análise da praxeologia do Peer Instruction (PI) construída nos permite identificar algumas características principais, que permeiam o bloco do tecnológico do método como um todo, são elas: a) a valorização do tempo em sala de aula; b) a ideia de que a compreensão conceitual é fundamental para o aprendizado de Física; c) a importância dos conhecimentos prévios do estudante para a construção da aprendizagem; e d) a noção de que a argumentação e o diálogo entre os colegas são fundamentais para a construção do conhecimento. No âmbito do bloco técnico-prático que constitui o PI, destacamos: a) a distribuição de materiais para o estudo prévio; b) a preparação da aula a partir do feedback dos estudantes; c) a apresentação de questões conceituais; d) a votação; e e) a discussão entre os colegas.

\section{Considerações Finais}

Neste estudo, analisamos as descrições do método Peer Instruction (PI) presentes no artigo de Araujo e Mazur (2013) e no livro de Mazur (2015) com o objetivo de construir uma Organização do Método de Ensino (OME), explicitando sua composição em termos da praxis e do logos. As atividades do PI foram estruturadas em oito tipos de tarefa (três para o momento extraclasse e cinco para a sala de aula), considerando o topos do professor. Para cada uma, 
foram identificas as técnicas sugeridas para resolvê-las e discursos tecnológicos que podem justificar, gerar e/ou explicar essas técnicas.

Os tipos de tarefa que, segundo a OME proposta, precisam ser realizadas pelo professor em uma aplicação do método indicam o protagonismo dado ao aluno no PI. Por exemplo, faz parte do conjunto de ações do professor: possibilitar a preparação prévia dos alunos $\left(\mathrm{T}_{1}\right)$, adaptar as aulas conforme a compreensão dos conceitos demonstrada por eles $\left(\mathrm{T}_{6}\right)$ e oportunizar que uns aprendam com os outros $\left(\mathrm{T}_{7}\right)$.

A partir do mapeamento da praxeologia, identificamos discursos tecnológicos que subjazem uma série de técnicas, compondo princípios pedagógicos característicos do PI. São eles: o tempo em sala de aula precisa ser valorizado com o engajamento ativo dos estudantes; a compreensão conceitual é fundamental para o aprendizado de Física; os conhecimentos prévios dos estudantes são essenciais para a aprendizagem; e a argumentação e o diálogo entre os colegas possibilitam a construção do conhecimento. Tais princípios, apoiados na OME de referência construída neste estudo, podem servir de base para acompanhar processos de transposição do PI para diferentes contextos educativos.

Uma das potencialidades da OME construída é permitir que um pesquisador interessado em analisar a implementação do método possa identificar as transformações que ele sofre ao ser transposto para um contexto particular, possibilitando analisar se tais modificações facilitam a adequação da proposta a uma realidade específica, mantendo princípios essenciais do método, ou se descaracterizam a proposta.

Além disso, de posse da estrutura praxeológica do PI, pode-se propor articulações e comparações entre o método e pressupostos oriundos de referenciais baseados em teorias de aprendizagem, ampliando suas potencialidades. De modo similar, pode-se pensar na composição de metodologias de ensino mais amplas ao articular o PI com outros métodos de ensino, observando pressupostos teóricos convergentes e divergentes entre eles e possíveis ações para compatibilizá-los. Para isso, é também oportuna a realização da análise praxeológica para outros métodos de ensino.

Por fim, destacamos que a OME apresentada é uma interpretação possível para a estrutura do método, não única ou exclusiva. Outras praxeologias, edificadas com a ferramenta analítica proposta por Espinosa, Araujo e Veit (2019), podem ser construídas e posteriormente comparadas com a exposta no presente artigo, abrindo caminho para o diálogo e uma compreensão mais aprofundada de práticas docentes viabilizadas com o Peer Instruction.

\section{Agradecimentos}

Agradecemos a Renan Sonaglio por seus comentários e sugestões que contribuíram para a melhoria deste trabalho.

Ives Solano Araujo agradece ao CNPq pela bolsa de produtividade em pesquisa concedida. 


\section{Referências}

ARAUJO, I. S.; MAZUR, E. Instrução pelos colegas e ensino sob medida: uma proposta para o engajamento dos alunos no processo de ensino-aprendizagem de Física. Caderno Brasileiro de Ensino de Física, Florianópolis, v. 3, n. 2, p. 362-384, 2013. Disponível em: https://doi.org/10.5007/2175-7941.2013v30n2p362. Acesso em: 21 dez. 2020.

BARROWS, H. S.; TAMBLYN, M. R. Problem-Based Learning: An Approach to Medical Education. New York: Springer, 1980.

BENDER, W. N. Aprendizagem Baseada em Projetos: Educação diferenciada para o Século XXI. 1. ed. Porto Alegre: Penso Editora, 2014.

CHEVALLARD, Y. El análisis de las prácticas docentes en la teoría antropológica de lo didáctico. Recherches en Didactique des Mathématiques, Lyon, v. 19, n. 2, p. 221-266, 1999. Disponível em:

https://edisciplinas.usp.br/pluginfile.php/118315/mod_resource/content/1/articulo_chevallar d_TAD_1999.pdf. Acesso em: 14 jan. 2021.

CHEVALLARD, Y. Introducing the Anthropological Theory of the Didactic: an attempt at a principled approach. Hiroshima Journal of Mathematics Education, Hiroshima, v. 12, p. 71-114, 2019.

DANCY, M. H.; HENDERSON, C.; TURPEN, C. How faculty learn about and implement researchbased instructional strategies: The cas of Peer Instruction. Physical Review Physics Education Research, online, v. 12, n. 1, p. 010110(17), 2016. Disponível em: https://link.aps.org/doi/10.1103/PhysRevPhysEducRes.12.010110. Acesso em: 6 jan. 2021.

ESPINOSA, T. Adoção de inovações didáticas no ensino universitário de Física na perspectiva de Transposições Praxeológicas. 2019. Tese (Doutorado em Ensino de Física) - Universidade Federal do Rio Grande do Sul - UFRGS, Porto Alegre, 2019. Disponível em: https://lume.ufrgs.br/handle/10183/188433. Acesso em: 7 dez. 2020.

ESPINOSA, T.; ARAUJO, I. S.; VEIT, E. A. Análisis Praxeológico de los Métodos de Enseñanza: un Puente entre la Investigación y la Práctica. Revista Brasileira de Pesquisa em Educação em Ciências, Belo Horizonte, v. 19, p. 373-397, 2019.

HENDERSON, C. The challenges of instructional change under the best of circumstances: a case study of one college physics instructor. American Journal of Physics, College Park, v. 73, n. 8, p. 778-786, 2005.

HENDERSON, C.; DANCY, M. H. Impact of physics education research on the teaching of introductory quantitative physics in the United States. Physical Review Special Topics - Physics Education Research, online, v. 5, n. 2, p. 020107, 2009. Disponível em: https://journals.aps.org/prper/abstract/10.1103/PhysRevSTPER.5.020107. Acesso em: 6 jan. 2021.

MAZUR, E. Peer instruction : a user's manual. $1^{\text {a }}$ ed. Upper Saddle River, NJ: Prentice Hall, 1997. v. 1. Disponível em: https://doi.org/10.1063/1.881735 
MAZUR, E. Peer Instruction: a revolução da aprendizagem ativa. Porto Alegre: Penso, 2015.

MAZUR, E.; WATKINS, J. Just-in-Time Teaching: Across the disciplines, across the academy. Sterling: Stylus Publishing, 2010.

MICHAELSEN, L. K.; KNIGHT, A. B.; FINK, L. D. Team-Based Learning: A transformative use of small groups in college teaching. Sterling: Stylus Publishing, 2004.

MÜLLER, M. G. et al. Uma revisão da literatura acerca da implementação da metodologia interativa de ensino Peer Instruction (1991 a 2015). Revista Brasileira de Ensino de Física, online, v. 39, n. 3, p. e3403, 2017. Disponível em: https://www.scielo.br/j/rbef/a/Vv8MmjJWmm5B3HjJ8hYwKCJ/abstract/?lang=pt. Acesso em: 27 jan. 2021.

NOVAK, G. M.; GAVRIN, A.; CHRISTIAN, W. Just-in-Time Teaching: Blending active learning with web technology. 1. ed. Upper Saddle River: Prentice Hall, 1999.

TULLIS, J. G.; GOLDSTONE, R. L. Why does peer instruction benefit student learning? Cognitive Research: Principles and Implications, online, v. 5, n. 15, p. 1-12, 2020. Disponível em: https://cognitiveresearchjournal.springeropen.com/articles/10.1186/s41235-020-00218-5.

Acesso em: 18 nov. 2020.

TURPEN, C.; DANCY, M. H.; HENDERSON, C. Perceived affordances and constraints regarding instructors' use of Peer Instruction: Implications for promoting instructional change. Physical Review Physics Education Research, online, v. 12, n. 1, p. 010116, 2016. Disponível em: https://journals.aps.org/prper/abstract/10.1103/PhysRevPhysEducRes.12.010116. Acesso em: 2 jan. 2021.

WINSL $\varnothing \mathrm{W}, C$. Anthropological Theory of didactic phenomena: some examples and principles of its use in the study of mathematics education. In: CONGRESO INTERNACIONAL SOBRE LA TAD, 3. , 2011, Bellaterra. Un panorama de la TAD. Bellaterra: Centre de Recerca Matemàtica, 2011. p. 117-138. Disponível em: http://www.atd-tad.org/documentos/un-panorama-de-la-tad-anoverview-atd/. Acesso em: 12 jan. 2021. 